\title{
Prediction of Health Promoting Behaviors Through the Health Locus of Control in a Sample of Adolescents in Iran
}

\author{
Zahra Hosseini, ${ }^{1}$ Teamur Aghamolaei, ${ }^{1,}{ }^{*}$ and Amin Ghanbarnejad ${ }^{1}$ \\ ${ }^{1}$ Social Determinants on Health Promotion Research Center, Hormozgan University of Medical Sciences, Bandar Abbas, IR Iran \\ "Corresponding author: Teamur Aghamolaei, Social Determinants in Health Promotion Research Center, Hormozgan University of Medical Sciences, Bandar Abbas, IR Iran. Tel: \\ +98-7633338583, Fax: +98-7633338584, E-mail: teaghamolaei@gmail.com
}

Received 2016 May 24; Revised 2016 July 12; Accepted 2016 August 14.

\begin{abstract}
Background: Health promoting behaviors are amongst the best methods through which people can maintain and control their health.

Objectives: The aim of this study was the prediction of health promoting behaviors through the health locus of control in a sample of adolescents in Bandar Abbas, in the south of Iran.

Methods: In this cross-sectional study, the Wallston questionnaire and adolescent health promoting scale were used for data collection. From the 378 distributed questionnaires among the students, 342 questionnaires were completed and returned (response rate $=90.5 \%$ ). Pearson correlation coefficient and multiple linear regressions were used to analyze the data by the SPSS 19 software. Results: The mean age of the subjects was $16.1 \pm 1.1$ years. Overall, $44.7 \%$ were male. The results showed that $12 \%$ of changes in health promoting behaviors were predicted by the health locus of control (including internal locus of control, chance and the powerful others $)\left(P<0.001, F=15.5, R^{2}=0.12\right)$. Among the predictive factors, the internal locus of control $(B=0.25, P<0.001)$ and powerful others $(\mathrm{B}=0.16, \mathrm{P}<0.01)$ significantly predicted health promoting behaviors.

Conclusions: Strengthening the internal locus of control and following up the advices of individuals like physicians and health experts are recommended to promote the health behaviors of students.
\end{abstract}

Keywords: Health Locus of Control, Health Promoting Behaviors, Students, Iran

\section{Background}

In Iran, adolescents (age group between 11 and 19 years old) constitute about 16 million (27\%) of the population (1). Adolescence is a unique period in life (2) and is one of the most challenging periods of human's growth (3).

During this developmental period, some changes take place in the condition of the body, mind, and social relations and the individual reaches a physical, mental and sexual evolution and gradually takes the responsibility of his/her health (4). The changes occurring during adolescence expose teenagers to the risk of developing highrisk health behaviors (5). Teenagers do not consider hygiene and health as important issues in life, as much as adults. Their perspective to the world is different from that of adults. Teenagers usually behave in a way that exposes them to fatal diseases. For example, one-fourth of the newly identified cases of acquired immunodeficiency syndrome (AIDS) and sexually transmitted infections are observed amongst teenagers. Moreover, during adolescence other behaviors such as smoking, decrease in physical activity, and poor eating habits are initiated, which can later cause chronic diseases (6). Hence, the health of adolescents and youth is dependent on their health-related be- haviors. (7). Many experts believe that teenagers' problems and issues are mainly behavioral. On the other hand, almost all normal and abnormal behaviors of adults originate from their adolescence, which can affect the individual's whole life (8).

Promotion of healthy behaviors is one of the best ways through which people can maintain and control their health (9). The statistics regarding the main causes of mortality indicate that $53 \%$ of deaths is due to people's lifestyles and unhealthy behaviors (10).

Health promoting behaviors are one of the most important determinants of health, and are recognized as the underlying cause in preventing many diseases and promotion of health. Therefore disease prevention is directly related to these behaviors (11). Health-promotion has a potential long-term effect on the quality of life through extending lifespan, decreasing expenses of health care, and increasing national production $(12,13)$. It includes behaviors such as proper nutrition, regular exercise, avoiding destructive behaviors, protection against accidents, early diagnosis of diseases, control of emotions, positive feelings and thoughts, management of stress and other psychosocial problems, and promotion of interpersonal and social relationships (14-16). 
Many researchers believe that doing health promoting behaviors and consequently having a healthy lifestyle is significantly related to the extension of life span and life expectancy (17).

Considering the fact that adolescence is a period during which the social personality of individuals is formed, in this period disorders such as vulnerability towards psychological disturbances can affect the individual's capabilities, and consequently his/her future and destiny. Hence, paying attention to the adolescents' mental health is of great importance. Besides to maintain children's physical health, the risk factors of their mental and psychological well-being should be identified and controlled (18).

Moreover, the belief that adolescents may not acquire psychological disorders has caused many teenagers with lack of mental health to be neglected by health and hygiene authorities. Unfortunately, according to recent reports, this group of the society benefits the least from programs related to the prevention of psychological diseases $(19,20)$.

On the other hand, most of the health problems are interconnected with human behaviors. Behavioral theories and models can be utilized for understanding how to prevent health problems (21). In case individuals do not have the ability to recognize healthy reactions, when encountering life challenges, they instead show deflective behaviors for solving the problems (22). The health locus of control theory is an instrument, which can be applied to identify the individual's control type. This theory was derived from the Bandura social learning theory by Rater. He designed the framework of the control source and introduced internal and external controls (23).

People with internal control source believe that their experiences is under the control of their skills and struggles, and people with external control source believe that their successes and failures are due to chance, luck and fortune (24). The health control source influences the individuals' expectations, hopefulness and health, and can affect all physical, emotional, intellectual, social, and physiological aspects of people $(25,26)$.

In health education, it is important to consider the concept of health control source for creating messages tailored to the target population. Hence, in creation of messages for motivation of people towards healthy behaviors, psychological indicators of decision-making in the target population should be considered for performing healthy behaviors (27).

\section{Objectives}

Considering the importance of health promoting behaviors and health locus of control, the aim of this study was the prediction of health promoting behaviors through health locus of control in a sample of adolescents in Bandar Abbas, a city in the south of Iran.

\section{Methods}

The population of this cross-sectional study was high school students in Bandar Abbas, a city in the south of Iran in 2015. Overall, 378 students were selected through a multi stage sampling method. To do this, 10 schools, including five male and five female high schools were randomly selected. Then, in each school, the subjects were selected based on the number of students. All of the students who volunteered to participate in the study and filled out the questionnaires were included in the study and students, who were not willing to participate in the study or filled out the questionnaires incompletely, were excluded. Before the study, the subjects were informed of the objective of the study and confidentiality of their data.

To determine the condition of health locus of control, the Wallston questionnaire was used (28). This questionnaire consists of three forms including A, B and C. In this study the form $A$ of the questionnaire was used, which is more appropriate for demographic studies. This questionnaire measures internal and external health locus of control. The external health locus of control includes chance and powerful others (like physicians, etc.). This questionnaire includes 18 items. Six items are related to the internal locus of control with a score ranging from 6 to 36. Moreover, six items are related to chance, and six items are related to powerful others with scores also ranging between 6 and 36. All answers are in a six choice Likert scale format, from strongly agree (6) to strongly disagree (1). Higher score in each domain indicates a higher internal or external control, higher chance, or higher influence of powerful others (physician, etc.). The validity and reliability of this questionnaire has previously been reviewed and approved in Iran (29).

To determine the condition of health promoting behaviors, the adolescent health promotion scale was used. This scale includes 40 items specially designed for adolescents with answers on a five-point Likert scale. This scale evaluates the performance of health promoting behaviors in six domains including social support (seven items), spiritual growth (eight items), health responsibility (eight items), stress management (seven items), nutritional behaviors (six items), and physical activity (four items) (30). The validity and reliability of this scale has been reviewed and approved in Iran (31).

Health locus of control sources were considered as independent variables and health promoting behaviors considered as dependent variables. 
Data were analyzed using SPSS19 statistical software. To compare the health locus of control and health promoting behaviors between male and female students, independent sample t-test was used. To predict health-promoting behaviors through health locus of control, multiple linear regressions with the Enter method was used.

\section{Results}

From the 378 distributed questionnaires among the students, 342 questionnaires were filled out completely and thus were analyzed (Response rate $=90.5 \%$ ). The mean age of the subjects was 16.1 years $(\mathrm{SD}=1.1)$ ranging from 14 to 18 . Overall, $44.7 \%$ of the subjects were male and $55.3 \%$ were female. Most of them (33\%) were studying in the second grade of high school.

The health locus of control of the subjects was more internal than external, and in the external health locus of control, the subjects had a stronger belief on powerful others rather than on chance. There were no significant differences between male and female students regarding the health locus of control domains (Table 1).

Regarding health promoting behaviors, there were significant differences between male and female students in nutrition and exercises domains, and in these domains health-promoting behaviors were better among male students compared to female students. In other domains of health promoting behaviors, there was no significant difference between different genders (Table 2).

To consider if there is any correlation between health locus of control and health promoting behaviors, the Pearson correlation coefficient was used. The results indicated that there was a significant correlation between internal health locus of control and powerful others $(\mathrm{P}<0.001)$. Moreover, the internal locus of control and powerful others had positive significant correlations with the health promoting behaviors $(\mathrm{P}<0.001)$ (Table 3$)$.

To predict health-promoting behaviors through health locus of control, multiple linear regressions with the Enter method were used. Based on the results of regression analysis with the dependent variable of health promoting behaviors, and predictive variables of health locus of control domains, $12 \%$ of changes in health promoting behaviors were predicted by the health locus of control (including internal locus of control, chance and powerful others $(\mathrm{P}<$ $\left.0.001, \mathrm{~F}=15.5, \mathrm{R}^{2}=0.12\right)$. Among the predictor variables, the internal locus of control $(\mathrm{B}=0.25, \mathrm{P}<0.001)$, and powerful others $(B=0.16, P<0.01)$ significantly predicted health promoting behaviors. The subjects, who had more internal locus of control and believed more in powerful others were more likely to have health-promoting behaviors. The contribution of internal locus of control to the prediction of health promoting behaviors was more than the contribution of powerful others (Table 4).

\section{Discussion}

Based on the results, the lowest mean score of health locus of control belonged to chance and the highest score belonged to internal locus of control and powerful others. People with an external health locus of control believed that the specific outcomes and events in their lives were related to powerful others like physicians, chance, destiny and faith. On the other hand, people with internal health locus of control believe that specific outcomes and events of their lives is the result of their own behaviors and deeds and the determinant of their health is directly their own behavior and deeds (28). Considering the results of the present study, adolescents believe that their health is mainly related to their own behaviors and deeds, and after that it is related to powerful people like physicians. In addition, they don't consider chance and faith as important and effective factors influencing their health. These results are in line with the results of a study by Aghamolaei et al. on the adult population of Bandar Abbas (32).

As the results showed, there was no significant difference between male and female students, regarding health locus of control, while in the study of Kuwahara et al. (33) females received higher scores in chance and powerful others compared to males. Moreover, in a study by Cohen et al. (34), females showed lower internal locus of control compared with males. Differences in cultural structure, beliefs and values of societies can be a pribable reason for some of these conflicts.

Also the results of the regression analysis indicated that among the predictive variables, the internal locus of control and powerful others, significantly predict health promoting behaviors. So that an increase in the scores of internal locus of control and powerful others causes an increase in health promoting behaviors. Regarding the internal locus of control, the results of the present study were consistent with the results of similar studies $(25,32$, $35,36)$. It can be concluded that the stronger the internal health locus of control, the higher health promoting behaviors, which subsequently leads to prevention of diseases. People, who obtain higher scores in internal locus of control in comparison with those that obtain higher scores in external locus of control, are more likely to follow behaviors, which prevent diseases and promote their health. They have a higher inclination for following preventive behaviors like observing good eating habits and doing medical examinations (37). The results of a study by Grotz et al. (38) indicated that people with higher scores in chance had lower rate of exercise and physical activity, showed less 
Table 1. Comparison of Health Locus of Control Between Male And Female Students

\begin{tabular}{|c|c|c|c|c|c|}
\hline \multirow[t]{2}{*}{ Locus of Control } & \multirow[t]{2}{*}{ Total, Mean \pm SD } & \multicolumn{2}{|c|}{ Gender } & \multirow[t]{2}{*}{$\mathbf{t}$} & \multirow[t]{2}{*}{ PValue } \\
\hline & & Male, Mean $\pm S D$ & Female, Mean \pm SD & & \\
\hline Internal & $28.4 \pm 4.5$ & $28.3 \pm 4.9$ & $28.4 \pm 4.2$ & -0.11 & 0.91 \\
\hline Chance & $21.6 \pm 6.4$ & $21.4 \pm 6.7$ & $21.8 \pm 6.2$ & -0.59 & 0.55 \\
\hline Powerful others & $26.2 \pm 5.4$ & $26.3 \pm 5.4$ & $26.1 \pm 5.4$ & 0.31 & 0.75 \\
\hline
\end{tabular}

Table 2. Comparison of Health Promoting Behaviors Between Male and Female Students

\begin{tabular}{|c|c|c|c|c|c|}
\hline \multirow[t]{2}{*}{ Behavior } & \multirow[t]{2}{*}{ Total, Mean \pm SD } & \multicolumn{2}{|c|}{ Gender } & \multirow[t]{2}{*}{$\mathbf{T}$} & \multirow[t]{2}{*}{ P Value } \\
\hline & & Male, Mean \pm SD & Female, Mean \pm SD & & \\
\hline Nutrition & $3.63 \pm 0.69$ & $3.81 \pm 0.73$ & $3.50 \pm 0.63$ & 4.15 & $<0.001$ \\
\hline Social support & $3.42 \pm 0.68$ & $3.36 \pm 0.65$ & $3.47 \pm 0.70$ & -1.45 & 0.14 \\
\hline Health responsibility & $3.43 \pm 0.71$ & $3.51 \pm 0.72$ & $3.36 \pm 0.70$ & 1.92 & 0.06 \\
\hline Spiritual growth & $4.14 \pm 0.63$ & $4.13 \pm 0.71$ & $4.15 \pm 0.56$ & -0.32 & 0.74 \\
\hline Exercises & $2.89 \pm 0.98$ & $3.39 \pm 0.94$ & $2.49 \pm 0.82$ & 9.43 & $<0.001$ \\
\hline Stress management & $3.67 \pm 0.73$ & $3.66 \pm 0.80$ & $3.68 \pm 0.67$ & -0.28 & 0.77 \\
\hline
\end{tabular}

Table 3. The Correlation Coefficients of Health Locus of Control and Health Promoting Behaviors

\begin{tabular}{|c|c|c|c|}
\hline & Internal & Chance & Powerful Others \\
\hline Internal & - & & \\
\hline Chance & 0.166 & - & \\
\hline Powerful others & $0.497^{\mathrm{a}}$ & $0.381^{\mathrm{a}}$ & - \\
\hline Health promoting behaviors & $0.322^{\mathrm{a}}$ & 0.042 & $0.264^{\mathrm{a}}$ \\
\hline
\end{tabular}

${ }^{\mathrm{a}} \mathrm{P}<0.001$.

Table 4. Prediction of Health Promoting Behavior Through the Health Locus of Control

\begin{tabular}{lccc}
\hline Variables & SD & Beta & Confidence Interval \\
\hline Internal locus of control & 0.006 & 0.25 & $(0.014,0.038)$ \\
Chance locus of control & 0.004 & -0.06 & $(-0.013,0.003)$ \\
Power others' locus of control & 0.006 & 0.16 & 0.001 \\
\hline
\end{tabular}

care of their teeth, and did not commonly search for health information. In the study of Holm et al. (39), the health locus of control was not a predictor of mammographybehavior. In the study of Steptoe et al. (40), people with higher scores in internal locus of control showed better health behaviors, but higher scores in chance was associated with a decrease in health behaviors, which is in agreement with the results of this study. The results of a study by Norman et al. (41) indicated that higher scores in internal health locus of control led to higher scores in health-related behaviors such as doing exercise and following a proper diet. With increase in internal health locus of control, the rate of health related behaviors increases, while with an increase in chance and powerful others, the rate of health behaviors will decrease.

\subsection{Conclusion}

It can be concluded that internal locus of control and powerful others are the main predictors of health promoting behaviors in adolescents. Therefore, to promote health behaviors in adolescents, strengthening the internal locus of control and following up the advices of people like physicians and health experts, is recommended.

\section{Acknowledgments}

The authors would like to thank the research deputy of Hormozgan University of Medical Sciences for their financial support. The authors also like to express their gratitude to the students, who participated in the study 


\section{Footnotes}

Authors' Contribution: Project manager, designer of the research and collaborator in collecting data, Teamur Aghamolaei; collaborator in analyzing data and writing the paper, Zahra Hosseini and Amin Ghanbarnejad.

Funding/Support: This study was financially supported by research deputy of Hormozgan University of Medical Sciences, Bandar Abbas.

\section{References}

1. Malek Afzali H. Basic training in reproductive health. Tehran: Family Planning Association of the Islamic Republic of Iran; 2001.

2. Salmaani Barough N, Pashaeypour S, Rezaiepour A, Kazemnejad A. Study of quality of snacking in adolescents (12-18 years old). Hayat. 2006;12(4):21-9.

3. Mahan LK, Escott Stump S. Krause's food, nutrition, and diet therapy. 11 ed. USA: Saunders; 2004.

4. Hosein Nejad M, Aziz zadeh Forozi M, Mohammad Alizadhe S, Haghdoost A. Role of Self Efficacy Predictors in Nutritional Behaviors of Kerman High School Female Students in 2006-2007 Academic Year. J Shahid Sadoughi Univ Med Sci. 2008;16(3):49-56.

5. Rezaeipour A, Youssefi F, Mahmoudi M, Shakeri M. Relationship between Adolescents' Nutritional and Physical Activity Behaviors with their Perceptions about Parents' Lifestyle Behaviors. Hayat. 2007;13(3):17-25.

6. Stanhope M, Lancaster J. Community health nursing: Process and practice for promoting health. USA: Mosby; 1992.

7. Brener ND, Collins JL, Kann L, Warren CW, Williams BI. Reliability of the Youth Risk Behavior Survey Questionnaire. Am J Epidemiol. 1995;141(6):575-80. [PubMed: 7900725].

8. Amini K, Amini A, Madani H, Pourmemari M, Fallah R. Investigation of Oral and Dental-Care Procedures in High School Students of Zanjan Province - 2005. Zanjan Univ Med Sci J. 2006;14(54):47-55.

9. Shabbidar S, Fathi B, Mousavi Shirazifard N. Effects of clinical nutrition education on glycemic control outcomes in type 2 diabetes. Int J Diab Dev Ctries. 2006;26(4):157. doi:10.4103/0973-3930.33181.

10. Shaban M, Mehran A, Taghlili F. Relationship between perception of health concept and health promoting behaviors: A comparative study among Tehran university medical and non-medical Students. Hayat. 2007;13(3):27-36.

11. Aghamolaei T, Eftekhar H, Mohammad K. Application of health belief model to behavior change of diabetic patients. Payesh. 2005;4(4):2639.

12. Aggleton P, Chalmers H. Nursing models and nursing practice. 2 ed. UK: Macmillan; 2000.

13. Tabari R. Nursing models and nursing practice. Tehran: Boshra;2004. pp. 83-100.

14. Ahmadi Abhari A, Mirzaei E. An invitation to health. Tehran: Ketabkhane Farvardin; 1997.

15. Andrews GR. Promoting health and function in an ageing population. BMJ. 2001;322(7288):728-9. [PubMed: 11264216].

16. Habibi A, Neekpoor S, Seyedolshohda M, Haghani H. Health promotion behaviours and Quality of life among elderly people: A crosssectional survey 2006. J Ardabil University of Med Sci. 2008;8(1):29-36.

17. Mahmoudi A. Effects of self care planning on reduction of $\mathrm{A} 1 \mathrm{C}$ hemoglobin in adults with diabetes mellitus. Med Sci J Azad Univ Tehran Med Branch. 2006;16(3):171-6.

18. Roberts RE, Attkisson CC, Rosenblatt A. Prevalence of psychopathology among children and adolescents. Am J Psychiatry. 1998;155(6):71525. doi: 10.1176/ajp.155.6.715. [PubMed: 9619142].
19. Hacker K, Drainoni ML. Mental health and illness in Boston's children and adolescents: One city's experience and its implications for mental health policy makers. Public Health Rep. 2001;116(4):317-26. doi: 10.1016/s0033-3549(04)50053-5.

20. Potts Y, Gillies ML, Wood SF. Lack of mental well-being in 15-yearolds: an undisclosed iceberg?. Fam Pract. 2001;18(1):95-100. [PubMed: 11145637].

21. Luquis RR, Garcia E, Ashford D. A qualitative assessment of college students' perceptions of health behaviors. Am J Health Stud. 2003;18(2/3):156-64.

22. Kann L, Kinchen SA, Williams BI, Ross JG, Lowry R, Grunbaum JA, et al. Youth Risk Behavior Surveillance-United States, 1999. State and local YRBSS Coordinators. J Sch Health. 2000;70(7):271-85. [PubMed: 10981282].

23. Kleinke CL. Coping with life challenges. 2nd Edition ed. Pacific Grove. USA: Cole Publishing Company; 1998.

24. Taylor MC, Boss MW. Locus of control and course completion in adult basic education. Adult Literacy Basic Edu. 1985;9(1):18-23.

25. Rotter JB. Generalized expectancies for internal versus external control of reinforcement. Psychol Monogr. 1966;80(1):1-28. [PubMed: 5340840].

26. Schwarz S. Abnormal Psychology, Mountain View. Denmark: Mayfield Publishing Company; 2000.

27. Grantz M. Do you have the power to succeed? Locus of control and its impact on education Miami: Miami University; 1999. Available from: http://www.units.miamioh.edu/psybersite/control/education.shtml.

28. Wallston KA, Strudler Wallston B, De Vellis R. Development of the Multidimensional Health Locus of Control (MHLC) Scales. Health Educ Behav. 1978;6(1):160-70. doi:10.1177/109019817800600107.

29. Moshki M, Ghofranipour F, Hajizadeh E, Azadfallah P. Validity and reliability of the multidimensional health locus of control scale for college students. BMC Public Health. 2007;7(1):295. doi: 10.1186/1471-24587-295. [PubMed: 17942001].

30. Chen MY, Lai LJ, Chen HC, Gaete J. Development and validation of the short-form Adolescent Health Promotion Scale. BMC Public Health. 2014;14(1):1106. doi: 10.1186/1471-2458-14-1106. [PubMed: 25344693].

31. Tavaffian S, Aghamolaei T. Assessing Lifestyle of high school students in Bandar Abbas, Iran. J School Public Health Ins. 2014;11(3):83-93.

32. Aghamolaei T, Tavafian S, Ghanbarnejad A. Health Locus of Control and Its Relation with Health-Promoting Behaviors among People over 15 in Bandar Abbas, Iran.J Health Admin. 2014;17(55).

33. Kuwahara A, Nishino Y, Ohkubo T, Tsuji I, Hisamichi S, Hosokawa T. Reliability and validity of the Multidimensional Health Locus of Control Scale in Japan: relationship with demographic factors and healthrelated behavior. Tohoku J Exp Med. 2004;203(1):37-45. [PubMed: 15185970].

34. Cohen M, Azaiza F. Health-promoting behaviors and health locus of control from a multicultural perspective. Ethn Dis. 2007;17(4):636-42. [PubMed: 18072372].

35. Malcarne VL, Drahota A, Hamilton NA. Children's Health-Related Locus of Control Beliefs: Ethnicity, Gender, and Family Income. Children Health Care. 2005;34(1):47-59. doi:10.1207/s15326888chc3401_4.

36. Ozolins AR, Stenstrom U. Validation of health locus of control patterns in Swedish adolescents. Adolescence. 2003;38(152):651-7. [PubMed: 15053492].

37. Hatamloo Sadabadi M, Poursharifi H, Babapour Kheiroddin J. The role of health locus of control on self-care behaviors in patients with type II Diabetes. Med J Tabriz Univ Medi Sci. 2011;33(4):17-22.

38. Grotz M, Hapke U, Lampert T, Baumeister H. Health locus of control and health behaviour: results from a nationally representative survey. Psychol Health Med. 2011;16(2):129-40. doi: 10.1080/13548506.2010.521570. [PubMed: 21328142].

39. Holm CJ, Frank DI, Curtin J. Health beliefs, health locus of control, and women's mammography behavior. Cancer Nurs. 1999;22(2):14956. [PubMed: 10217031]. 
40. Steptoe A, Wardle J. Locus of control and health behaviour revisited: a multivariate analysis of young adults from 18 countries. BrJPsychol. 2001;92(Pt 4):659-72. [PubMed: 11762867].
41. Norman P, Bennett P, Smith C, Murphy S. Health locus of control and health behaviour. J Health Psychol. 1998;3(2):171-80. doi: 10.1177/135910539800300202. [PubMed: 22021357]. 